\title{
Divergent Inflammatory, Fibrogenic, and Liver Progenitor Cell Dynamics in Two Common Mouse Models of Chronic Liver Injury
}

Julia Köhn-Gaone, ${ }^{*}$ Benjamin J. Dwyer, ${ }^{*}$ Candice A. Grzelak, ${ }^{\dagger}$ Gregory Miller, ${ }^{\dagger}$ Nicholas A. Shackel, ${ }^{\dagger \S}$ Grant A. Ramm, ${ }^{\ddagger \top}$ Geoffrey W. McCaughan, ${ }^{\dagger \S \|}$ Caryn L. Elsegood, ${ }^{* * *}$ John K. Olynyk, ${ }^{* \dagger \dagger \neq \ddagger}$ and Janina E.E. Tirnitz-Parker* ${ }^{\star \S \S}$

\begin{abstract}
From the School of Biomedical Sciences, * Curtin Health Innovation Research Institute, Curtin University, Bentley, Western Australia; the Centenary Institute of Cancer Medicine and Cell Biology, ${ }^{\dagger}$ Camperdown, New South Wales; the Faculty of Medicine and Biomedical Sciences, ${ }^{\ddagger}$ The University of Queensland, Brisbane, Queensland; the Royal Prince Alfred Hospital, ${ }^{\S}$ Camperdown, New South Wales; the QIMR Berghofer Medical Research Institute, ${ }^{\Uparrow}$ Brisbane, Queensland; the A.W. Morrow Gastroenterology and Liver Centre," Sydney, New South Wales; the School of Chemistry and Biochemistry, ** University of Western Australia, Crawley, Western Australia; the Fremantle and Fiona Stanley Hospitals, ${ }^{\dagger \dagger}$ Murdoch, Western Australia; the School of Veterinary and Life Sciences, ${ }^{\ddagger \ddagger}$ Murdoch University, Murdoch, Western Australia; and the School of Medicine and Pharmacology, ${ }^{\S \S}$ University of Western Australia, Fremantle, Western Australia, Australia
\end{abstract}

Accepted for publication March 10, 2016.

Address correspondence to Janina E.E. Tirnitz-Parker, Ph.D., School of Biomedical Sciences, Curtin University, Kent St., Bentley, Western Australia 6102, Australia. E-mail: n.tirnitz-parker@curtin. edu.au.

\begin{abstract}
Complications of end-stage chronic liver disease signify a major cause of mortality worldwide. Irrespective of the underlying cause, most chronic liver diseases are characterized by hepatocellular necrosis, inflammation, fibrosis, and proliferation of liver progenitor cells or ductular reactions. Vast differences exist between experimental models that mimic these processes, and their identification is fundamental for translational research. We compared two common murine models of chronic liver disease: the choline-deficient, ethioninesupplemented (CDE) diet versus thioacetamide (TAA) supplementation. Markers of liver injury, including serum alanine transaminase levels, apoptosis, hepatic fat loading, and oxidative stress, as well as inflammatory, fibrogenic and liver progenitor cell responses, were assessed at days $3,7,14,21$, and 42 . This study revealed remarkable differences between the models. It identified periportal injury and fibrosis with an early peak and slow normalization of all parameters in the CDE regimen, whereas TAA-treated mice had pericentral patterns of progressive injury and fibrosis, resulting in a more severe hepatic injury phenotype. This study is the first to resolve two different patterns of injury and fibrosis in the CDE and TAA model and to indisputably identify the fibrosis pattern in the TAA model as driven from the pericentral vein region. Our data provide a valuable foundation for future work using the CDE and TAA regimens to model a variety of human chronic liver diseases. (Am J Pathol 2016, 186: 1762-1774; http://dx.doi.org/10.1016/j.ajpath.2016.03.005)
\end{abstract}

Chronic liver diseases (CLDs), including viral hepatitis infection, alcoholic and nonalcoholic fatty liver disease, steatohepatitis, cholestasis, and hemochromatosis, are associated with hepatocyte injury and varying degrees of inflammation and fibrosis that predispose patients to hepatocellular carcinoma (HCC) development. Often multiple risk factors with potentially additive effects are coexistent, such as combinations of viral hepatitis, diabetes, and excessive alcohol consumption, ${ }^{1}$ and because therapy approaches are still limited, preventative and curative new treatment targets are urgently required.

Despite potentially distinct clinical presentations and being independent of the underlying cause, most CLDs share the common feature of ductular reactions. The term ductular reaction refers to the cellular component (ie, ductular epithelial cell structures that expand and are often

Supported by a collaborative research grant provided from the A.W. Morrow Gastroenterology and Liver Centre, Sydney, NSW, Australia, and National Health and Medical Research (NHMRC) project grant APP1031330 (G.A.R., J.K.O., J.E.E.T.-P.). J.K.-G. is the recipient of a Curtin Strategic International Postgraduate Research Scholarship. G.A.R. and J.K.O. are supported by a NHMRC Senior Research Fellowship (APP1061332) and Practitioner Fellowship (APP1042370), respectively. C.L.E. is supported through NHMRC project grant APP1042368.

J.K.-G. and B.J.D. contributed equally to this work.

Disclosures: None declared. 
accompanied by proliferation of facultative liver progenitor cell [LPC] arrangements). However, ductular reactions also encompass the inflammatory, vascular, neural, and extracellular matrix changes that are induced contemporarily in this injury niche. ${ }^{2,3}$ This compartment is activated when the liver is continuously affected by viral, toxic, or carcinogenic stimuli and hepatocytes either undergo replicative arrest or cannot meet the demand for generation of new functional cells. On activation, LPCs proliferate, migrate toward the injury site, and differentiate into the two main hepatic cell lineages, hepatocytes or cholangiocytes, depending on the disease type and consequent tissue needs. ${ }^{4-8}$ The LPC origin and the cells' lineage commitment, maturation capacity, and overall contributions to tissue regeneration remain highly controversial and are generally thought to be injury context-specific. ${ }^{9}$ These processes are regulated by the local microenvironment, which includes cell-cell and cellmatrix interactions in close association with hepatic stellate cell (HSC) activation and inflammation. ${ }^{10-14}$ Because of their high regenerative potential, LPCs have been suggested as promising candidates for cell transplantation, gene therapy, or bioartificial devices to treat gastrointestinal diseases. ${ }^{4,15}$ Importantly, it has been established that ductular reactions and LPC activation are intricately linked to CLD progression, revealing a strong positive correlation between the magnitude of the proliferative response and the severity of inflammation and fibrosis. ${ }^{16-19}$ In addition, pharmacologic inhibition of the LPC compartment decelerates disease progression and reduces HCC formation. ${ }^{20-22}$ Consequently, LPCs represent promising cellular targets to therapeutically influence disease outcome.

Several murine injury models have been developed to study CLD. A choline-deficient and ethionine-supplemented (CDE) diet is widely used in mice to examine steatosis, chronic inflammation, fibrosis, LPC proliferation, and HCC formation if administered long term. ${ }^{7,21,23-25}$ Hepatotoxicity is induced through the deficiency of choline, which is critical for the assembly and secretion of very low-density lipoproteins, ${ }^{26}$ combined with the hepatocarcinogen ethionine. A more recently adapted murine model is based on thioacetamide (TAA) administration, which can be delivered orally or via i.p. injection. TAA is metabolized to TAA sulfine and subsequently activated to the hepatotoxic compound sulfene. ${ }^{27}$ This metabolic transformation is mediated by the microsomal flavin-adenine dinucleotide-containing monooxygenase and the P450 cytochrome enzyme CYP2E1 and generates the reactive oxygen species superoxide anion and hydrogen peroxide, resulting in oxidative stress, which in turn leads to lipid peroxidation and centrilobular necrosis. ${ }^{28}$ TAA supplementation has traditionally been used to study fibrosis, cirrhosis, and the development of liver tumors, especially cholangiocarcinoma, when administered long term. ${ }^{12,29,30}$

The induction, severity, and progression of CLD vary greatly among animal models, depending on the underlying mechanisms. It is therefore vital to understand the molecular and histopathologic patterns to select the most appropriate regimen and time points to mimic the human disease. Thus, our aim was to compare the dynamics of liver injury and the inflammatory, fibrogenic, and progenitor cell responses in two common mouse models of CLD-CDE versus TAA administration.

\section{Materials and Methods}

\section{Animal Models}

Six-week-old male C57BL/6J mice (Animal Resources Centre, Murdoch, Australia) were housed on wheaten chaff bedding and kept on 12-hour day/night cycles in individually ventilated cages. Randomly grouped mice were exposed to experimental conditions with free access to either a choline-deficient diet (MP Biomedicals, NSW, Australia) with drinking water that contained $0.15 \%$ DL-ethionine (Sigma-Aldrich, Castle Hill, NSW, Australia) as previously described (CDE $\operatorname{diet}^{23}$ ) or normal chow with water that contained $300 \mathrm{mg} / \mathrm{L}$ of TAA (Sigma-Aldrich). ${ }^{12}$ Control animals received normal chow and drinking water. Liver tissue and serum were harvested on days $3,7,14,21$, and 42. All animal experiments were performed in accordance with the Australian code for the care and use of animals for scientific purposes at Curtin University, Perth, Australia, with local animal ethics committee approval.

\section{Histology and Immunohistochemistry Experiments}

Formalin-fixed, paraffin-embedded (FFPE) liver tissue (Amber Scientific, Midvale, WA, Australia) was used for histology and immunohistochemistry experiments or embedded in ornithine carbamoyltransferase (Sakura Finetek, South Holland, the Netherlands) and snap-frozen for immunofluorescent staining experiments. Sections of FFPE tissues were cut at $4 \mu \mathrm{m}$, dewaxed, and rehydrated according to standard protocols. Frozen sections $(7 \mu \mathrm{m})$ were fixed in cold methanol/acetone (VWR, Brisbane, QLD, Australia) for 5 minutes, air-dried, and rehydrated in phosphate-buffered saline before antibody labeling. Primary antibodies were diluted in antibody diluent (Dako, North Sydney, NSW, Australia) as follows: rat anti-A6 (1:200, gift from Dr. Valentina Factor, National Cancer Institute, Bethesda, MD), mouse anti- $\alpha$ smooth muscle actin ( $\alpha$-SMA; $1: 500$, Sigma-Aldrich), rat antiCD11b (1:400, eBioscience, San Diego, CA), rat anti-CD45 (1:200, eBioscience), rat anti-CD133 (1:200, eBioscience), rat anti-CK19 (1:200, TROMA-III, Developmental Studies Hybridoma Bank, Iowa City, IA), rabbit anti-E-cadherin (1:200, Cell Signaling, Beverly, MA), rabbit anti-EpCAM (1:200, Abcam, VIC, Australia), rat anti-F4/80 (1:80, eBioscience), goat anti-hepatocyte nuclear factor $4 \alpha$ (1:400, Santa Cruz, Santa Cruz, CA), rabbit anti-Ki-67 (1:400, Cell Signaling), mouse anti-pan-cytokeratin (panCK) (1:300, Dako), and rabbit anti-panCK (1:300, Dako). Visualization was performed using the $\mathrm{LSAB}^{+}$kit (Dako) and DAB (Dako) for immunohistochemistry ( $\mathrm{F} 4 / 80^{+}$cells) or using Alexa Fluor 
dyes (Life Technologies, Scoresby, VIC, Australia) for fluorescent detection of cells positive for the markers A6, $\alpha$-SMA, $\mathrm{CD} 11 \mathrm{~b}, \mathrm{CD} 45, \mathrm{Ki}-67$, and panCK. Cell numbers were quantitated by manual cell counting in five nonoverlapping fields of view. Hematoxylin and eosin staining was performed using standard protocols.

\section{Real-Time RT-PCR}

Total RNA was extracted from snap-frozen liver tissue using TRIzol reagent (Life Technologies), and genomic DNA was removed using the RQ1 RNase-free DNase (Promega, Alexandria, NSW, Australia). RNA $(1 \mu \mathrm{g})$ was reverse transcribed using the Moloney Murine Leukemia Virus Reverse Transcriptase (M-MLV-RT), RNase H Minus, Point Mutant (Promega). Expression analysis was performed by SYBR Green-based real-time PCR using GoTaq qPCR Master Mix (Promega) and the ViiA 7 RealTime PCR System (Life Technologies). Primers used for genes of interest are listed in Table 1. Data were normalized to the housekeeping genes $18 S$ rRNA or Taf $4 \alpha$ and expressed relative to control mice.

\section{Serum Alanine Transaminase Assay}

Serum alanine transaminase levels were measured using the method of Sigma-Aldrich (St Louis, MO).

\section{Cholesterol Assay}

Approximately $50 \mathrm{mg}$ of snap-frozen liver tissue was homogenized, and cholesterol was extracted using the Amplex Red Cholesterol Assay Kit (Life Technologies), as per the manufacturer's instructions.

\section{Oil Red 0 Staining}

For staining of neutral triglycerides and lipids, 7- $\mu \mathrm{m}$-thick, frozen liver tissue sections were air-dried for 1 hour at room temperature, then fixed in ice-cold $4 \%$ paraformaldehyde (Sigma-Aldrich) for 5 minutes and dried again for 1 hour at room temperature. Sections were placed in $100 \%$ 1,2propanediol (VWR) for 5 minutes, then transferred into $0.5 \%$ Oil Red O (Sigma-Aldrich) in 1,2-propanediol and incubated for 8 minutes at $55^{\circ} \mathrm{C}$. After an incubation in $85 \% 1,2$ propanediol for 5 minutes, sections were washed twice in distilled water, counterstained with hematoxylin, and mounted with gelatin-based aqueous mounting media. Sections were evaluated with the Scanscope XT digital slide imager (Aperio Technologies, Sacramento, CA) and Aperio ImageScope software version 12.1 (Aperio Technologies) using an algorithm-based positive pixel count in five nonoverlapping fields of view at $\times 400$ total magnification. Positive pixel counts are expressed as percentages.

\section{Apoptosis Assay}

Apoptotic cells were detected in 4- $\mu$ m-thick, FFPE liver sections using the fluorimetric terminal deoxynucleotidyl transferase-mediated dUTP nick-end labeling (TUNEL) assay according to the manufacturer's instructions (Promega). TUNEL ${ }^{+}$hepatocytes (identified by morphology) were quantified in five nonoverlapping fields of view at $\times 200$ total magnification.

\section{Sirius Red Staining}

Collagen deposition was visualized in $4-\mu$ m-thick, FFPE liver sections by Picrosirius Red staining according to the

Table 1 Primer Sequences and QuantiTect Primer Assays

\begin{tabular}{|c|c|c|c|}
\hline Genes of interest & Forward primer & Reverse primer & $\begin{array}{l}\text { QuantiTect primer assay } \\
\text { (Qiagen, Chadstone, } \\
\text { VIC, Australia) }\end{array}$ \\
\hline Mmp9 & 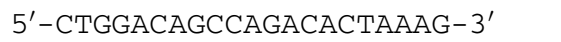 & $5^{\prime}-\mathrm{CTCGCGGCAAGTCTTCAGAG-3^{ \prime }}$ & \\
\hline Timp1 & $5^{\prime}$-ATTCAAGGCTGTGGGAAATG-3' & $5^{\prime}$-CTCAGAGTACGCCAGGGAAC- $3^{\prime}$ & \\
\hline$T g f b$ & $5^{\prime}$-GCGGACTACTATGCTAAAGAGG- $3^{\prime}$ & $5^{\prime}$-GTAGAGTTCCACATGTTGCTCC-3' & \\
\hline Rn18S & $5^{\prime}$-CGGCTACCACATCCAAGGAA-3' & $5^{\prime}$-GCTGGAATTACCGCGGCT-3' & \\
\hline$T x n$ & $5^{\prime}$-GCCAAAATGGTGAAGCTGAT-3' & 5'-TGATCATTTTGCAAGGTCCA-3' & \\
\hline Nqo1 & 5'-TATCСТTCCGAGTCATCTCTAGCA-3' & $5^{\prime}$-TCTGCAGCTTCCAGCTTCTTG-3' & \\
\hline Nrf1 & $5^{\prime}-$ AGCACGGAGTGACCCAAAC $-3^{\prime}$ & $5^{\prime}-$ TGTACGTGGCTACATGGACCT-3' & \\
\hline Col1a1 & & & QT00162204 \\
\hline$H g f$ & & & QT00158046 \\
\hline Ifng & & & QT01038821 \\
\hline Il6 & & & QT00098875 \\
\hline$L t b$ & & & QT00107443 \\
\hline Mmp2 & & & QT00116116 \\
\hline Taf $4 a$ & & & QT01060661 \\
\hline Timp2 & & & QT00138558 \\
\hline $\operatorname{Tnf}$ & & & QT00104006 \\
\hline Tweak & & & QT01743252 \\
\hline
\end{tabular}


manufacturer's instructions (Polysciences Inc., Warrington, PA). Fibrosis patterns were determined by an independent, experienced clinical gastrointestinal pathologist.

\section{Hydroxyproline Assay}

To quantitate tissue collagen deposition, approximately 130 $\mathrm{mg}$ of snap-frozen liver tissue was homogenized in $1 \mathrm{~mL}$ of $6 \mathrm{~mol} / \mathrm{L} \mathrm{HCl}$ (VWR) for 20 hours at $95^{\circ} \mathrm{C}$. Samples were centrifuged at $13,000 \times g$ for 10 minutes, and $40 \mu \mathrm{L}$ of supernatant was used per reaction. Then $10 \mu \mathrm{L}$ of $10 \mathrm{~mol} / \mathrm{L}$ $\mathrm{NaOH}$ (Scharlau, Port Adelaide, SA, Australia) and $450 \mu \mathrm{L}$ of chloramine-T solution (127 mg of chloramine-T hydrate [Sigma-Aldrich] in $2 \mathrm{~mL} \mathrm{50 \%} \mathrm{n-propanol} \mathrm{[Sigma-Aldrich],}$ filled up to $10 \mathrm{~mL}$ with acetate citrate buffer that contained
$0.88 \mathrm{~mol} / \mathrm{L}$ sodium acetate tri-hydrate [Sigma-Aldrich], 0.24 $\mathrm{mol} / \mathrm{L}$ citric acid [Sigma-Aldrich], $0.2 \mathrm{~mol} / \mathrm{L}$ acetic acid [Sigma-Aldrich], $0.85 \mathrm{~mol} / \mathrm{L} \mathrm{NaOH}, \mathrm{pH} 6.5$ ) were added to each sample and incubated for 25 minutes at room temperature. Subsequently, $500 \mu \mathrm{L}$ of dimethylaminobenzaldehyde solution (1.5 $\mathrm{g}$ of 4-[dimethylamino] benzaldehyde [Sigma-Aldrich] in $10 \mathrm{~mL}$ of 2:1 n-propanol:perchloric acid mix [Sigma-Aldrich]) were added, and samples were incubated for 20 minutes at $65^{\circ} \mathrm{C}$ before absorbance measurement at $560 \mathrm{~nm}$.

\section{Statistical Analysis}

Quantitative data are presented as means \pm SEM with $n \geq 4$. Statistical significance was evaluated by the twotailed, unpaired $t$-test and considered significant at $P<0.05$.
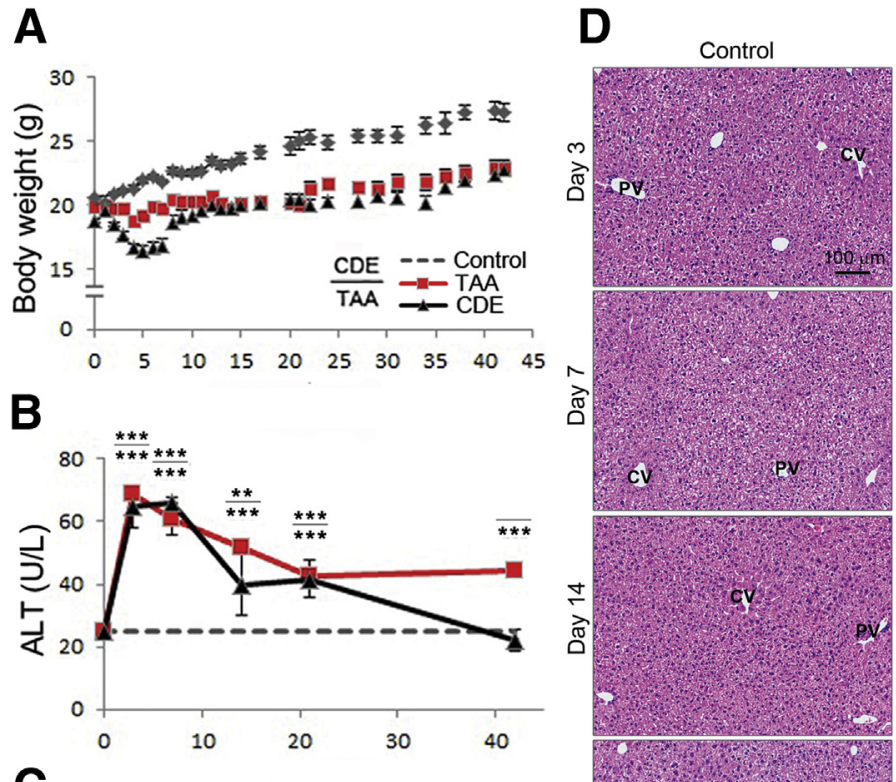
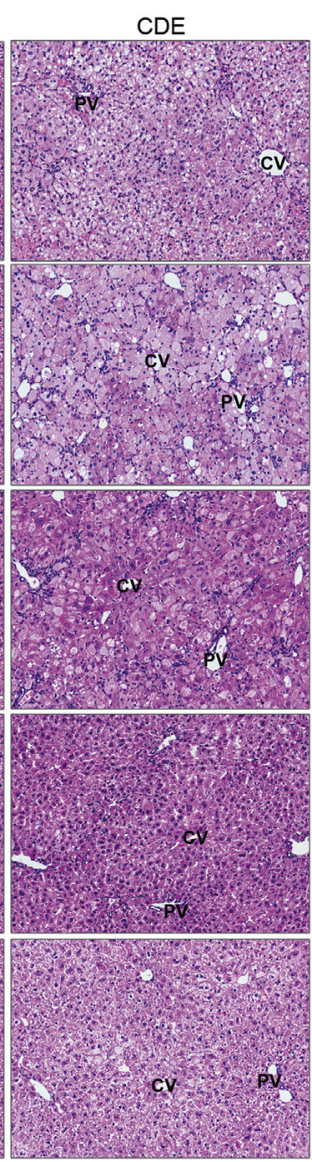

TAA

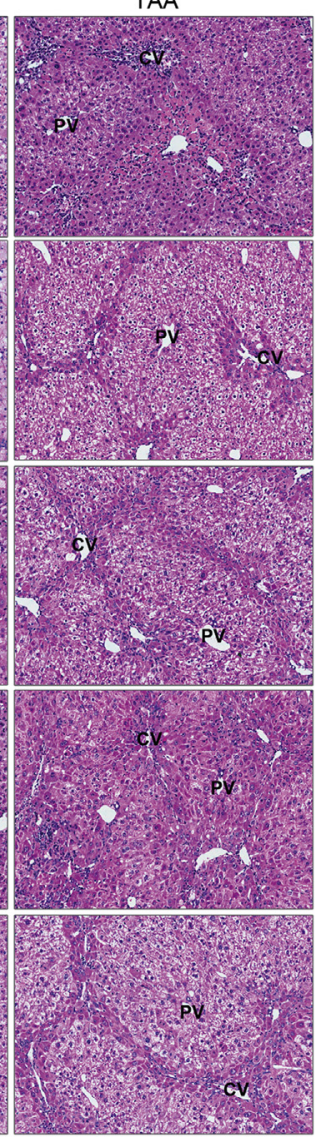

Figure 1 CDE- and TAA-induced chronic liver disease result in overall liver damage measured by body weight lost, morphologic changes, increased alanine transaminase levels, and enhanced apoptotic cell numbers. A: The body weight of CDE, TAA, and control mice was measured for 0 to 42 days. Both models induced weight loss during the first week; however, this loss was more severe after CDE administration. B: Liver damage was assessed biochemically by measuring serum alanine transaminase levels, revealing a significant increase in both regimens, peaking at day 3 . Alanine transaminase levels normalized to control levels after 6 weeks in CDE-fed mice but remained elevated after TAA exposure. C: Apoptotic cells were fluorescently labeled and quantified as terminal deoxynucleotidyl transferase-mediated dUTP nick-end labeling (TUNEL) ${ }^{+}$cell numbers in five FOVs per sample. Both models induced an increase in apoptotic cell numbers at day 3 and 7; however, TAA administration resulted in elevated apoptotic cell numbers throughout the time course. D: Formalin-fixed, paraffin-embedded liver sections of mice treated for $3,7,14,21$, and 42 days and respective controls were used for histologic assessment by hematoxylin and eosin staining. In CDE-fed mice, major tissue damage was observed during the induction phase (day 3 and 7), evenly distributed throughout the parenchyma, and returned to a normal-appearing morphology by day 42. TAA induced centrilobular tissue damage throughout the study, which progressed over time and resulted in a central-to-central organization. Data are expressed as means \pm SEM. $n=4$ to 6 mice per group. ${ }^{*} P<0.05,{ }^{*} P<0.01$, and ${ }^{* * *} P<0.001$ compared with control mice. Scale bar $=100 \mu \mathrm{m}$. Original magnification: $\times 100$ (D). CDE, choline-deficient, ethionine-supplemented; CV, central vein; FOV, field of view; PV, portal vein; TAA, thioacetamide. 


\section{Results}

\section{Divergent Tissue Damage Dynamics and Mechanisms in CDE- and TAA-Induced Liver Injury}

To establish and compare the dynamics of CDE- and TAAinduced liver injury, we first evaluated alterations to liver architecture, markers of hepatocyte health, and body weight as an indicator of overall animal health. Throughout the study, disease parameters were assessed on days 3 and 7 (induction phase), 14 and 21 (establishment phase), and 42 (maintenance phase).

We observed moderate weight loss of $5 \%$ to $10 \%$ in TAA-induced injury compared with the CDE regimen, which caused the animals to lose up to $20 \%$ of their initial body weight during the induction phase. After this initial adaptation period, body weights of mice on both liver injury protocols recovered but remained considerably lower than noninjured controls throughout the study (Figure 1A).

Histologic assessment of liver architecture revealed overt differences in morphology associated with CDE or TAA administration. Major tissue damage was seen in CDE mice throughout the liver during the induction phase marked by hepatocyte degeneration, cell enlargement, swelling, rounding, and sometimes hepatocyte ballooning. This finding was accompanied by periportal enrichment of small basophilic cells up to day 14 . The liver architecture then returned to normal hepatocyte and general lobular morphology during
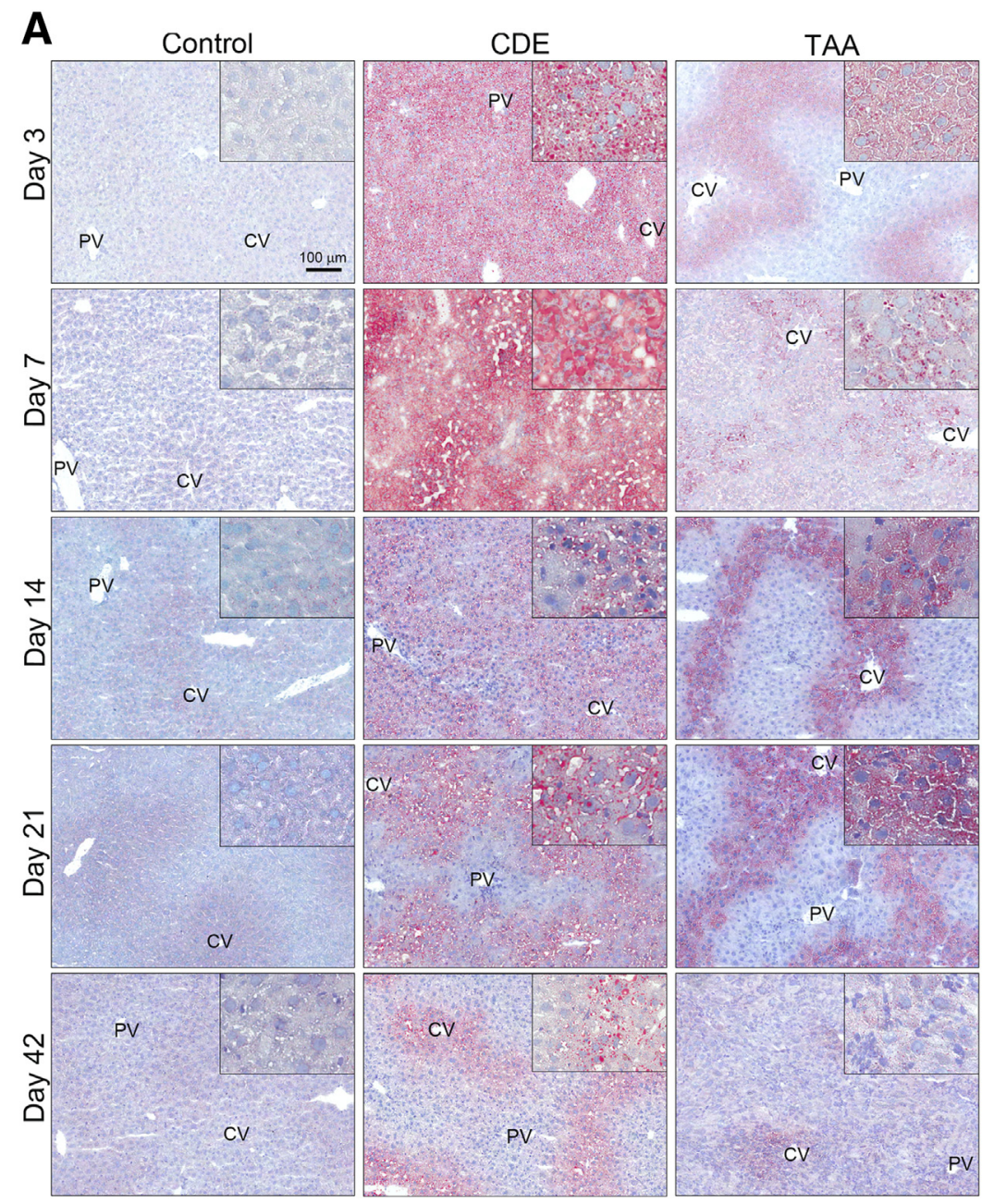

B
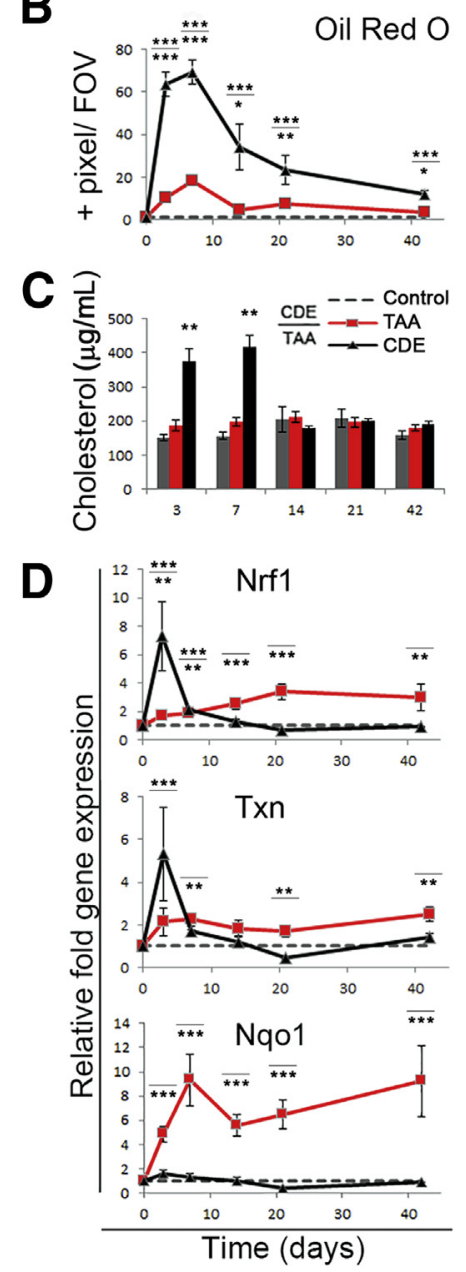

Figure 2 CDE and TAA exposure induces lipid accumulation and oxidative stress. Liver sections of CDE, TAA, and control mice were stained for lipids using Oil Red 0 on days $3,7,14,21$, and 42 (A) and quantified by positive $(+)$ pixel counts (expressed as percentage) in five FOVs per sample (B). Both CDE and TAA exposure induces rapid lipid accumulation on days 3 and 7 , more severely in response to CDE, and resolves toward day 42. In contrast to the CDE model that showed high fat loading throughout the liver parenchyma, TAA administration resulted in pericentral fat deposition with a strong zonal distribution. C: Homogenized liver tissue was used to measure cholesterol levels. The TAA model reveals no elevated cholesterol levels; however, CDE administration results in increased levels on days 3 and 7. D: 0xidative stress was assessed through transcriptomic analysis of Nrf1, Txn, and Nqo1 expression levels. CDE and TAA exposure induces elevated expression levels of Nrf1 and Txn at day 3. These levels decrease in the CDE model thereafter but remain elevated or progressively increased in the TAA model, which also indicates additional activation of Nqo gene expression. Data are expressed as means \pm SEM. $n=4$ to 6 mice per group. ${ }^{*} P<0.05,{ }^{* *} P<0.01$, and ${ }^{* * *} P<0.001$ compared with control mice. Scale bar $=100 \mu \mathrm{m}$. Original magnification: $\times 100$ (A, main images); $\times 400$ (insets). CDE, choline-deficient, ethionine-supplemented; CV, central vein; FOV, field of view; Nqo1, NADPH quinone oxidoreductase; Nrf1, nuclear factor (erythroidderived 2)-like 1; PV, portal vein; TAA, thioacetamide; Txn, thioredoxin. 
the maintenance phase (Figure 1D). In contrast, TAA provoked centrilobular tissue damage with significant basophilic cell enrichment and formation of eosinophilic bands of hepatocytes as early as day 3 , which remained unresolved during the study (Figure 1D).
Dynamic alterations to liver architecture in each liver injury model were reflected in quantitative biochemical assessments of liver damage. We observed significant increases in serum alanine transaminase levels, a reliable indicator of hepatocyte injury, peaking at 3 days in both injury
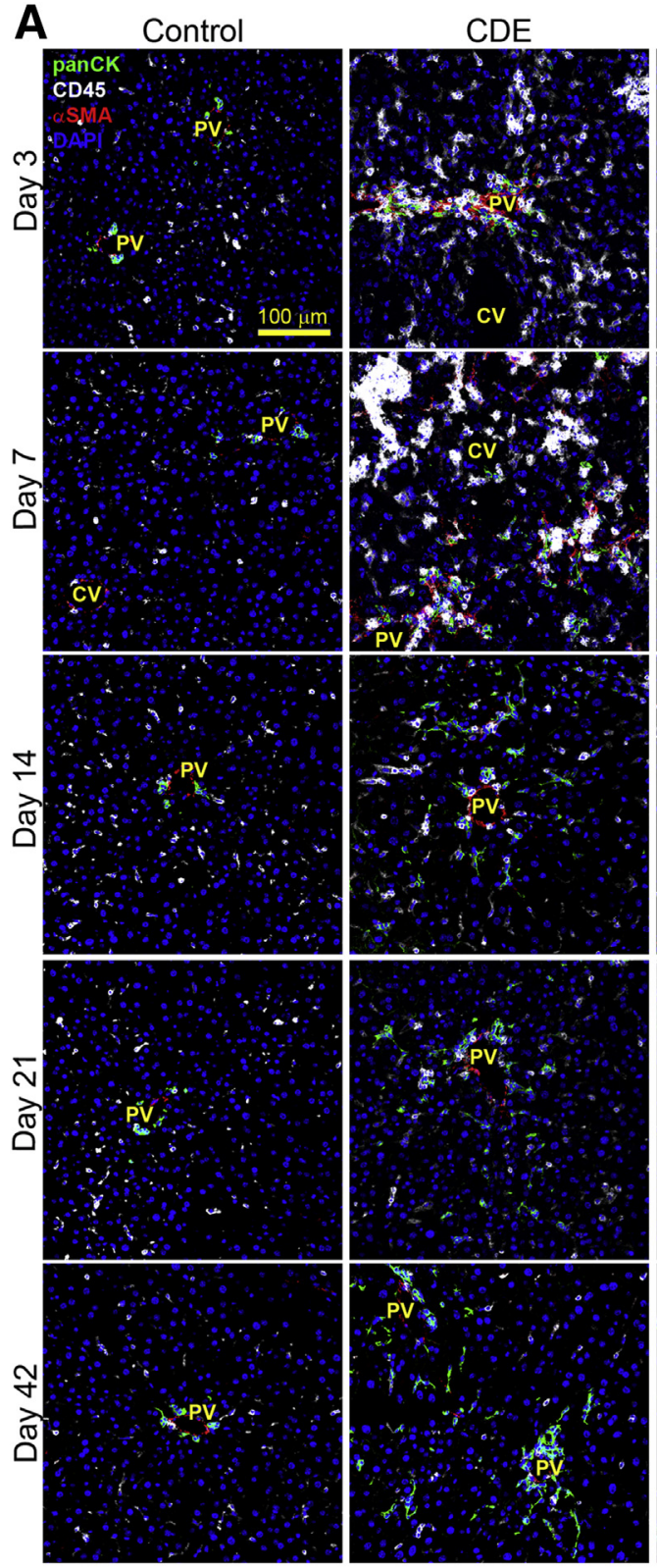
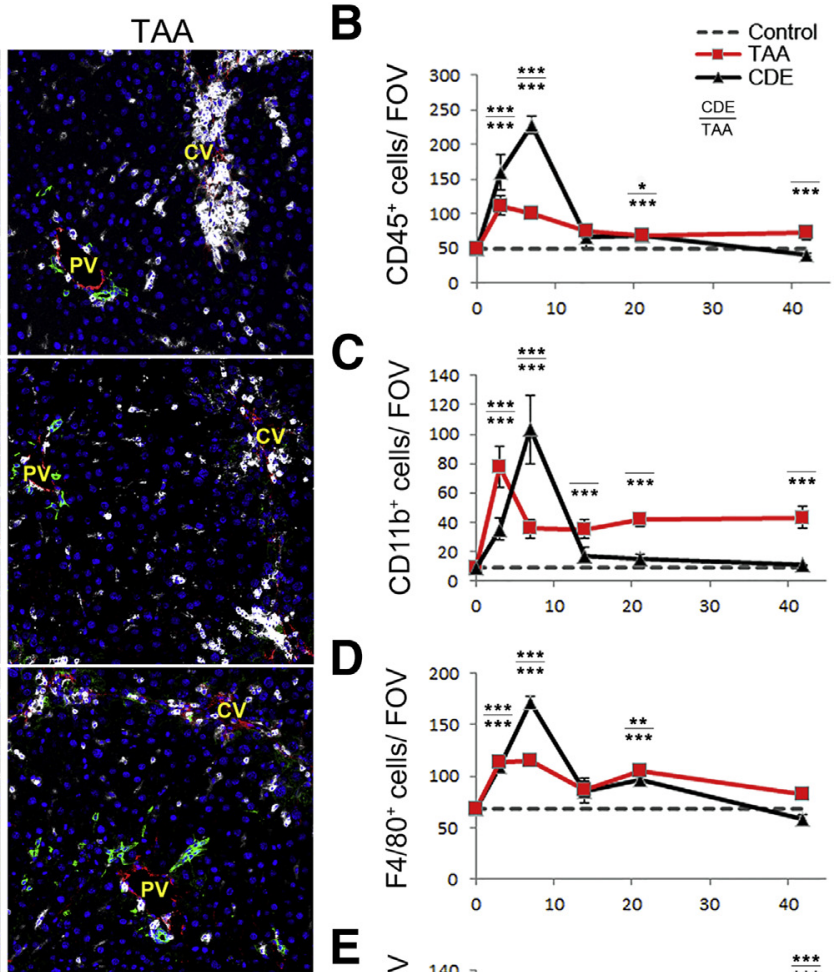

E

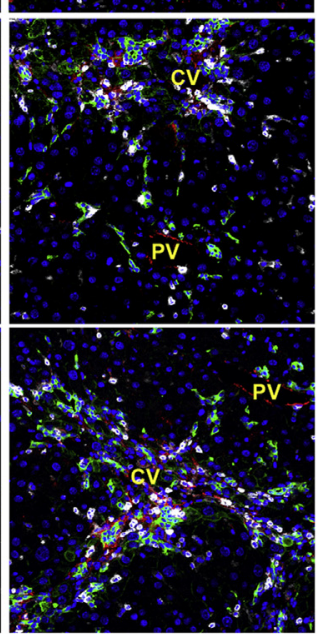

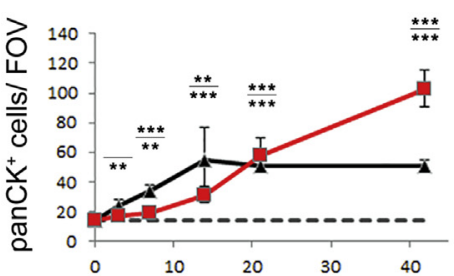

$\mathbf{F}$

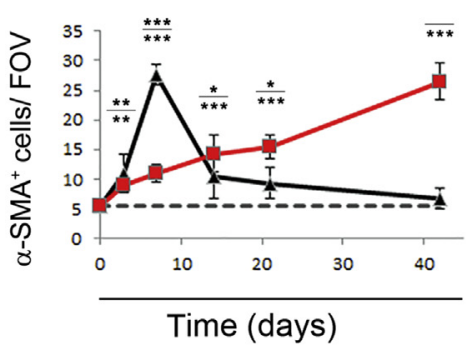

Figure 3 CDE- and TAA-induced tissue regeneration is mediated by the niche formation hosting LPCs, inflammatory cells, and activated HSCs as part of the ductular reaction. A: Control, CDE, and TAA liver sections of days 3, 7, 14, 21, and 42 were fluorescently labeled for the biliary cell and LPC marker panCK, inflammatory cell marker CD45, the activated HSC marker $\alpha$-SMA, and DAPI for nuclear quantitation. In the CDE model, CD45 ${ }^{+}$, panCK ${ }^{+}$, and $\alpha$-SMA ${ }^{+}$cells generated the regeneration niche in periportal areas during the induction phase, whereas the niche formation in response to TAA treatment was observed from day 21 onward located in centrilobular regions. Representative images are shown. Cells positively stained for CD45 (B), the monocyte-derived macrophage marker CD11b (C), the liver-resident Kupffer cell marker F4/80 (D), panCK (E), or $\alpha$-SMA (F), respectively, were quantified in five FOVs per sample. Both models induced an inflammatory response with increased $\mathrm{CD}_{4} 5^{+}, \mathrm{CD}_{11} \mathrm{~b}^{+}$, and $\mathrm{F} 4 / 80^{+}$cell numbers in the induction phase (CDE, day 7; TAA, day 3), which quickly returned to control levels in CDE-fed mice but remained elevated in response to TAA administration. PanCK ${ }^{+}$and $\alpha$-SMA ${ }^{+}$cell numbers increased progressively over time in TAA-fed mice. In the CDE model, panCK ${ }^{+}$cell numbers reach a steady-state level from day 14 onward, and $\alpha$-SMA $A^{+}$cells numbers peak at day 7 and return to control levels by day 42. Data are expressed as means \pm SEM. $n=4$ to 6 mice per group. ${ }^{*} P<0.05,{ }^{* *} P<0.01$, and ${ }^{* * *} P<0.001$ compared with controls. Scale bar $=100 \mu \mathrm{m}$. Original magnification: $\times 200($ A). $\alpha$-SMA, $\alpha$-smooth muscle actin; CDE, choline-deficient, ethionine-supplemented; CV, central vein; FOV, field of view; HSC, hepatic stellate cells; LPC, liver progenitor cell; panCK, pan-cytokeratin; PV, portal vein; TAA, thioacetamide. 
models (CDE, $64.9 \pm 6.6 \mathrm{U} / \mathrm{L}$; TAA, $68.7 \pm 0.34 \mathrm{U} / \mathrm{L}$ ). Serum alanine transaminase levels normalized to control levels after 6 weeks in CDE-treated mice $(22.13 \pm 3.6 \mathrm{U} / \mathrm{L})$ but remained elevated in the TAA model $(44.5 \pm 1.2 \mathrm{U} / \mathrm{L})$ (Figure 1B). Similarly, the number of $\mathrm{TUNEL}^{+}$apoptotic cells increased during the first 7 days in both regimens but resolved by day 42 in the CDE injury. Conversely, apoptotic cells further increased by day 21 and remained elevated throughout the TAA injury (Figure 1C).

Because we observed lipid accumulation in hepatocytes, a common histologic finding of human CLD biopsies that predisposes patients to further complications, we compared lipid deposition between the two models. Livers were stained with Oil Red $\mathrm{O}$, which detects lipids including mono-, di-, and triglycerides, phospholipid, and cholesterol. Mice exposed to TAA and CDE quickly induced substantial fatty changes in hepatocytes during the induction phase. The CDE model had significantly higher levels of lipid accumulation, resulting in macrovesicular and microvesicular hepatic steatosis throughout the parenchyma and resolving from portal areas over time. Conversely, TAA supplementation induced pericentral hepatic fat deposition with a strong zonal distribution (Figure 2, A and B).

We further examined hepatic lipid deposition by biochemically measuring total cholesterol levels as another indicator of steatosis. The hepatic cholesterol levels increased during the induction phase in CDE mice, consistent with the Oil Red $\mathrm{O}$-determined lipid level elevations, then returned to control levels in the establishment and maintenance phases. Surprisingly, and in contrast to Oil Red O-determined steatosis, cholesterol levels were not increased at any time in the TAA regimen (Figure 2C).

Because oxidative stress is implicated in the pathogenesis of CLDs that are associated with steatotic liver changes, we measured oxidative stress markers at the transcript level. Consistent with the detected hepatic lipid changes, expression levels of oxidative stress response mediator nuclear factor (erythroid-derived 2)-like $1^{31}$ and the antioxidant thioredoxin $^{32}$ were significantly elevated during the induction phase with a peak at day 3 (Figure 2D). As with previously assessed parameters of liver injury, oxidative stress quickly decreased after an early induction phase in CDE-fed mice but remained elevated or progressively increased in the TAA model, with additional activation of the sensitive redox indicator NADPH quinone oxidoreductase $1^{33}$ (Figure 2D).

\section{Injury-Specific Inflammatory Signatures Dictate} Disease Progression Patterns in the CDE- and TAA-Induced Liver Injury

We characterized the inflammatory response kinetics in these injury models by comparing the abundance of cells immunofluorescence positivity for leukocyte common antigen CD45. We also more specifically examined monocytemacrophage populations by immunohistochemical staining for F4/80 (liver-resident macrophages or Kupffer cells) and immunofluorescent staining for CD11b (monocyte-derived macrophages).$^{34}$ Both regimens induced a rapid inflammatory response, with $\mathrm{CD}_{4} 5^{+}$(Figure $3, \mathrm{~A}$ and $\mathrm{B}$ ), $\mathrm{CD} 11 \mathrm{~b}^{+}$ (Figure 3C and Supplemental Figure S1), and $\mathrm{F} 4 / 80^{+}$cell numbers (Figure 3D and Supplemental Figure S2) peaking at day 3 in the TAA and day 7 in the CDE model. The number of inflammatory cells then slowly returned toward control levels in both regimens but remained significantly elevated in TAA-treated mice. Both models induced increasing cell numbers of liver resident $\left(\mathrm{F} 4 / 80^{+}\right)$and infiltrating, monocyte-derived macrophage populations $\left(\mathrm{CD} 11 \mathrm{~b}^{+}\right)$in damaged lobular regions $(\mathrm{CDE}$, portal; TAA, central). Although this spatial arrangement persisted in the TAA model, the clustered localization of inflammatory cells reversed to an even lobular distribution from day 14 in CDEfed mice (Figure 3A and Supplemental Figures S1 and S2).

The early expansion of inflammatory cell numbers in both models was accompanied by rapid modulation of the liver microenvironment. We observed induction or significant increases in transcript expression levels of the proinflammatory cytokines tumor necrosis factor-like weak inducer of apoptosis, tumor necrosis factor, lymphotoxin $\beta$, IL-6, interferon- $\gamma$, and hepatocyte growth factor, which play a key role in hepatocyte survival and tissue remodeling during liver injury. Once again, in the CDE model,

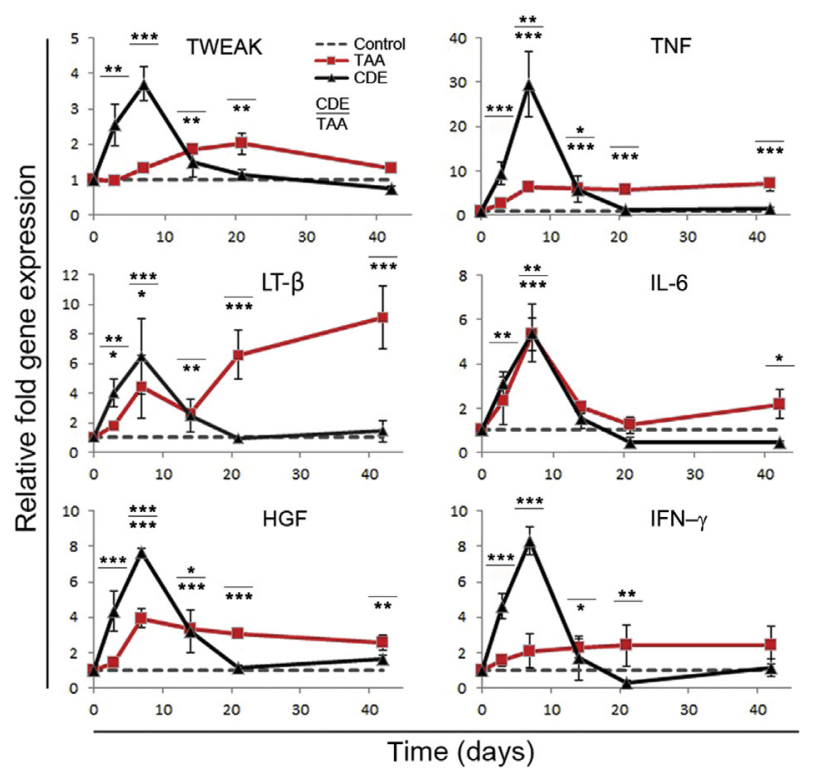

Figure 4 Inflammatory marker expression increases in CDE- and TAAinduced chronic liver disease. Real-time PCR data for mRNA expression levels of TNF, TWEAK, LT- $\beta$, IL- 6 , IFN- $\gamma$, and HGF were normalized. Both regimens create a proinflammatory and liver progenitor cell-favoring environment. CDE treatment induces increased expression levels, peaking at day 7 before normalizing to control levels. TAA administration results in gene expression levels, which remain elevated or progressively increase throughout the study. Data are expressed as means \pm SEM. $n=4$ to 6 mice per group. ${ }^{*} P<0.05,{ }^{*} P P<0.01$, and ${ }^{* *} P<0.001$ compared with controls. CDE, choline-deficient, ethionine-supplemented; HGF, hepatocyte growth factor; IFN- $\gamma$, interferon- $\gamma$; LT- $\beta$, lymphotoxin $\beta$; TAA, thioacetamide; TNF, tumor necrosis factor; TWEAK, TNF-like weak inducer of apoptosis. 
A
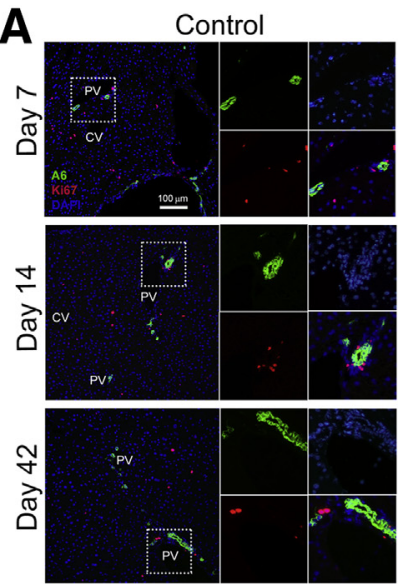

B

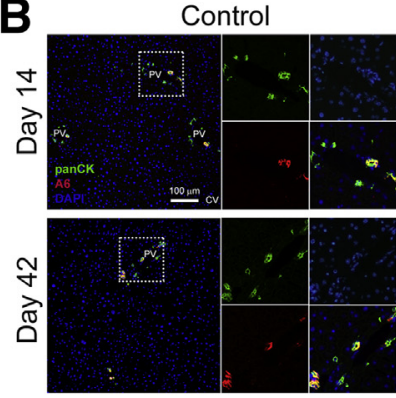

CDE
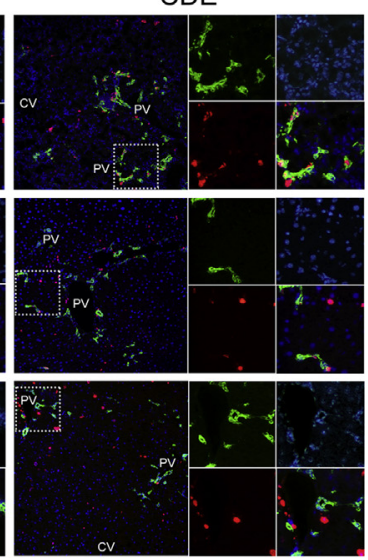

CDE

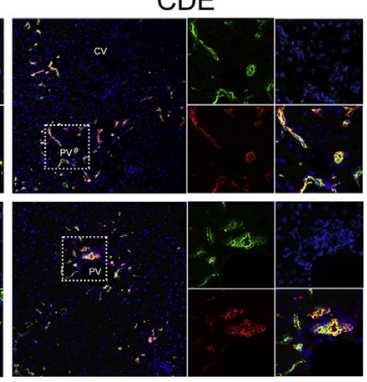

TAA
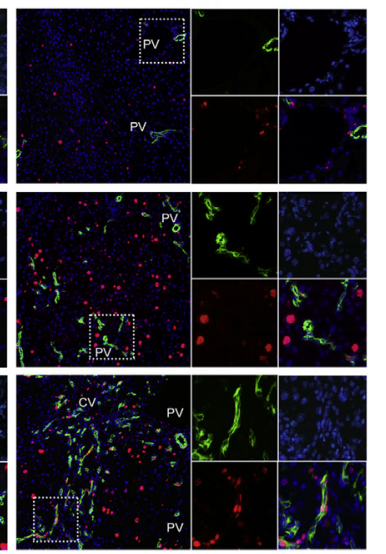

TAA

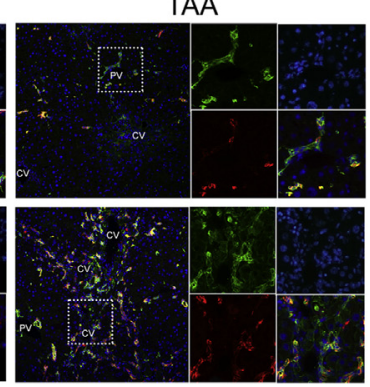

Figure 5 CDE and TAA treatments induce LPC proliferation and expansion of LPC subpopulations. A: Liver sections of CDE, TAA, and control mice were fluorescently labeled for the biliary cell and LPC marker A6 and the proliferation marker Ki-67. $\mathrm{CDE}$ exposure predominantly induces $\mathrm{A} 6^{+} / \mathrm{Ki}-67^{+}$ cells during the induction phase (day 7 ) where proliferating $\mathrm{A}^{+}$biliary structures and single LPCs migrate from periportal areas into the parenchyma. In the TAA model, $\mathrm{A} 6^{+} / \mathrm{Ki}-67^{+}$cells are mainly observed at later time points (day 42) as part of the centrally located ductular reaction. B: Liver sections were fluorescently labeled for the two biliary cell and LPC markers A6 and panCK. CDE treatment mainly generated the $\mathrm{A}^{+} / \mathrm{panCK}^{+}$cell subpopulation (shown for days 14 and 42), whereas in the TAA model the additional subpopulation $\mathrm{A}^{-} / \mathrm{panCK}^{+}$could be identified. Representative images are shown and dashed boxes identify the regions of enlarged images. Scale bar $=100 \mu \mathrm{m}$. Original magnification: $\times 100$; $\times 200$ (enlargements). CDE, choline-deficient, ethionine-supplemented; CV, central vein; LPC, liver progenitor cell; panCK, pan-cytokeratin; PV, portal vein; TAA, thioacetamide. expression levels normalized; however, they remained elevated in TAA-treated mice (Figure 4).

\section{The Regenerative Niches of CDE- and TAA-Induced Injury Display Temporal, Compositional, and Spatial Differences}

On the background of a significantly altered liver microenvironment, we investigated the organization of the cellular niche that we propose to mediate injury, fibrosis, and regeneration in most CLDs comprising i) injury-responsive inflammatory cells, ii) regenerative LPCs and/or ductular reactions, and iii) fibrosis-driving, activated HSCs (myofibroblasts). Immunofluorescent triple staining for CD45, the biliary cell and LPC marker panCK (distinguished by morphology) and the myofibroblast marker $\alpha$-SMA revealed a close spatial and temporal association among all three cell populations during the early induction phase in the CDE model. This niche was detected periportally, where numbers of panCK ${ }^{+}$cells peaked at 14 days after induction and maintained a steady state throughout the remaining 4 weeks. Strikingly, TAA treatment resulted in niche formation in centrilobular, rather than periportal regions. $\mathrm{PanCK}^{+}$biliary structures and LPCs, the majority of CD45 $5^{+}$ inflammatory cells, and $\alpha$-SMA ${ }^{+}$myofibroblasts were only observed in close association from approximately day 21 onward. Furthermore, numbers of panCK ${ }^{+}$cells progressively increased throughout the study (Figure 3).

The proinflammatory factors we found to be increased in the induction phase of both models (Figure 4) not only perpetuate the inflammatory response but also provide critical mitogens that activate the LPC compartment in a chronically injured liver. We therefore investigated LPC proliferation by identifying $\mathrm{A}^{+}$LPCs/biliary epithelium expressing the proliferation marker Ki-67. In addition, we co-stained for the two markers $\mathrm{A} 6$ and panCK to capture the dynamics of a broader ductular cell and LPC population. In control mice, A6 staining was restricted to the bile ducts, as expected. After $\mathrm{CDE}$ treatment, $\mathrm{A} 6^{+}$biliary structures and single LPCs proliferated from portal regions into the liver parenchyma, with $\mathrm{A} 6^{+} / \mathrm{Ki}-67^{+}$cells mainly being observed in the dynamic early phase of the LPC response. During the entire CDE period, few hepatocytes expressed $\mathrm{Ki}-67$, as judged by cell and nucleus morphology and lack of A6 expression (Figure 5). In contrast, with TAA supplementation, $\mathrm{A} 6^{+} / \mathrm{Ki}-67^{+}$structures were mainly detected at later time points, in particular on day 42 , when the inflammatory/ fibrogenic/LPC niche had been well established in pericentral areas, leading to substantial centrally localized ductular reactions. In addition, we observed many mitotically active $\mathrm{Ki}-67^{+}$hepatocytes (Figure 5A). Interestingly, when we compared the staining patterns for $\mathrm{A} 6$ and panCK, previously reported to detect $\mathrm{A}^{+}{ }^{+}$structures with a sensitivity of $>99 \%,{ }^{35}$ we discovered that the CDE and TAA models differed significantly. Although we observed a substantial overlap of both markers in CDE-treated mice at all investigated time points (shown for days 14 and 42), we identified numerous $\mathrm{A6}^{-} / \mathrm{panCK}^{+}$cells in the TAA regimen, some of which had the morphology of small intermediate hepatocytes and expressed hepatocyte nuclear factor $\alpha$ (Supplemental Figure S3). Again, it was clear that 
the expansion of biliary structures and the LPC compartment had shifted from the initial periportal localization in the induction phase to an accumulation in central areas at later time points (Figure 5B). We also assessed the emergence of panCK ${ }^{+}$ductular reactions defined by commonly used LPC markers, including CK19, CD133, epithelial cell adhesion molecule (EpCAM), and E-cadherin. ${ }^{9}$ All these markers identified ductular reactions (Supplemental Figures S4, S5, S6, and S7), with $\mathrm{EpCAM}^{+}$cells marking a subset of the $\mathrm{CK} 19^{+}$ductular reactions, consistent with previous studies reporting its use in antibody-based purification of a subpopulation of biliary cells with progenitor cell properties. ${ }^{5}$

\section{CDE- and TAA-Induced Injury Leads to Distinct Fibrogenic Responses}

Because the progression of most CLDs is associated with extracellular matrix remodeling and the excessive deposition of matrix proteins, it was of particular interest to compare fibrosis-associated processes in both models. These processes were evaluated in detail by transcriptomic analysis of fibrogenic markers, quantitation of activated HSC numbers, visualization of collagen deposition by Sirius Red staining, and biochemical hydroxyproline assessment.

Expression levels of the fibrosis-associated factors transforming growth factor- $\beta$, collagen I, matrix metalloproteinase 2 and 9, and tissue inhibitor of metalloproteinase 1 and 2

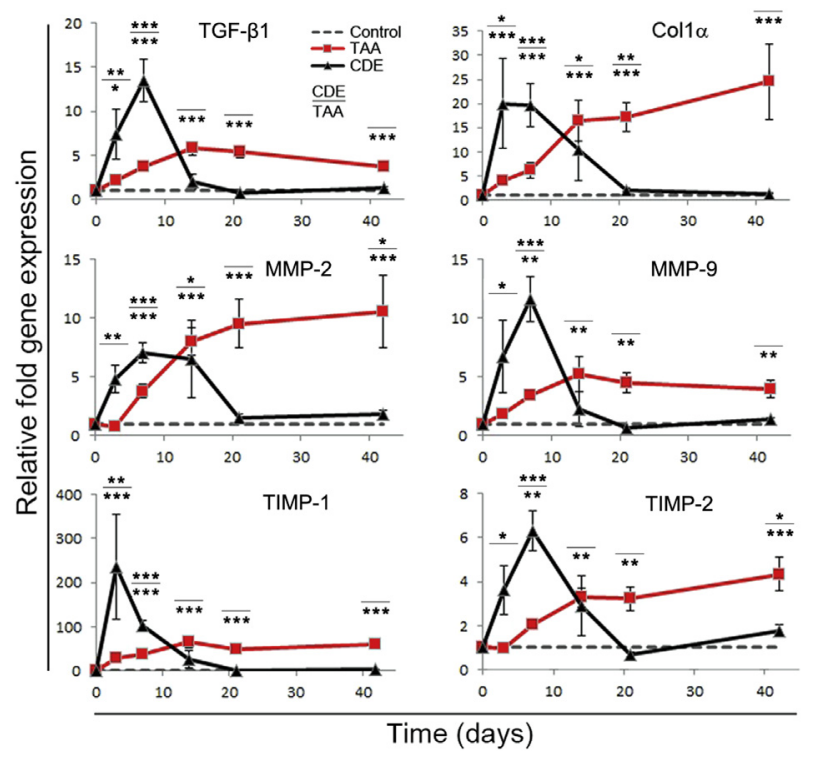

Figure 6 Fibrogenic marker expression is enhanced in CDE- and TAAinduced chronic liver disease. Data are normalized and expressed relative to control levels. CDE and TAA administration generates a fibrogenic environment, with peaking expression levels at day 3 or 7 in CDE-fed mice and maintenance of elevated or progressively increasing levels in the TAA model. Real-time PCR data for mRNA expression levels of TGF- $\beta 1$, Col $1 \alpha$, MMP- 2 and -9 , and tissue inhibitor of TIMP-1 and -2 are expressed as means \pm SEM. $n=$ 4 to 6 mice per group. ${ }^{*} P<0.05,{ }^{*} P<0.01$, and ${ }^{*} * * P 0.001$ compared with controls. CDE, choline-deficient, ethionine-supplemented; Col1 $\alpha$, collagen I $\alpha$; MMP, matrix metalloproteinase; TAA, thioacetamide; TGF- $\beta 1$, transforming growth factor- $\beta 1$; TIMP, tissue inhibitor of metalloproteinase. were significantly increased in both injury models. Increased expression of these factors was induced during the initial phase at day 3 and 7 and normalized thereafter in the CDE model. Conversely, consistent with previously investigated injury parameters, a mostly progressive increased expression in fibrosis-associated genes was observed in TAA-fed mice over the course of 6 weeks (Figure 6).

Because activated HSCs represent the main fibrosisdriving hepatic cell type, we assessed the number of $\alpha$-SMA ${ }^{+}$myofibroblasts in all phases of induced liver injury. Indeed, the quantitation results followed the same trend in both models, with an early peak and subsequent normalization of activated HSC numbers in CDE mice and a gradual significant increase in the TAA model (Figure 3F). Although HSCs were mainly activated in periportal regions during the induction phase of CDE treatment, they were localized to central areas in TAA-induced mice, revealing a cumulative organization pattern (Figure 3A).

We then examined gross collagen deposition and associated fibrosis patterns using the histopathologic stain Sirius Red. Thin layers of collagen surrounded the portal tracts and central veins in control mice and are a typical feature of a healthy liver. In contrast, both liver injury regimens induced significant collagen accumulation, albeit with very different dynamics and spatial organization. CDE exposure resulted in early portal fibrosis with chicken wire appearance in the induction phase, with normalization thereafter. However, TAA-treated livers had significant collagen deposition in central areas as early as day 3 after induction. The substantial pericentral fibrosis then progressed to form centralcentral septa in the late establishment and maintenance phase. In addition, portal-to-central bridging fibrosis was occasionally observed when portal and central fields were near each other during the later injury phases (Figure 7A).

Finally, biochemical examination of hepatic hydroxyproline content confirmed increased collagen deposition, consistent with previously established fibrosis-associated patterns. Thus, CDE-mediated collagen deposition peaked at day $7(225.1 \pm 7.4 \mathrm{ng} / \mathrm{mg}$ of liver tissue), and then subsequently resolved, whereas the TAA regimen stimulated a progressive collagen accumulation throughout the examined period, with the peak $(208.6 \pm 25.8 \mathrm{ng} / \mathrm{mg}$ of liver tissue) at day 42 of the maintenance phase (Figure 7B).

\section{Discussion}

The limitations in current treatment options for CLD patients, together with an ever-increasing unmet demand for transplant donor organs, make it necessary to explore new therapeutic avenues. Animal models are important tools to study CLD-associated mechanisms and to understand the biology of injury- and progression-driving factors. However, no animal model perfectly mirrors the pathogenesis of human disease; therefore, it is vital to thoroughly 
A
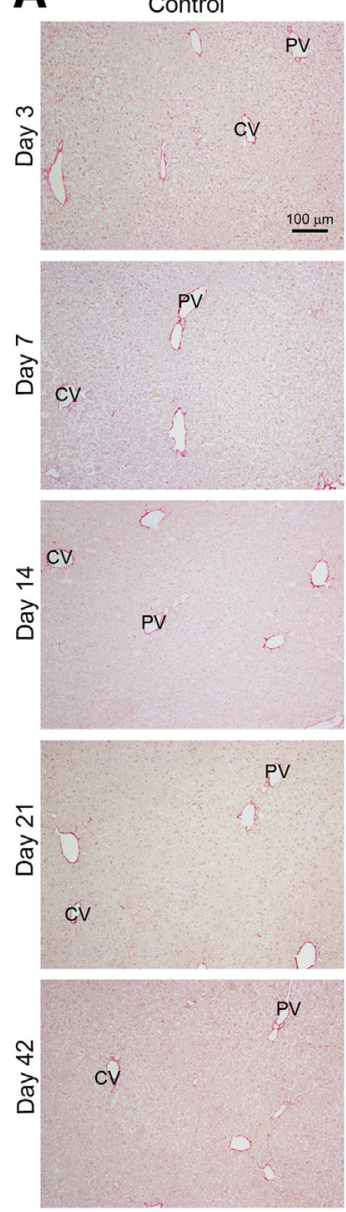

CDE
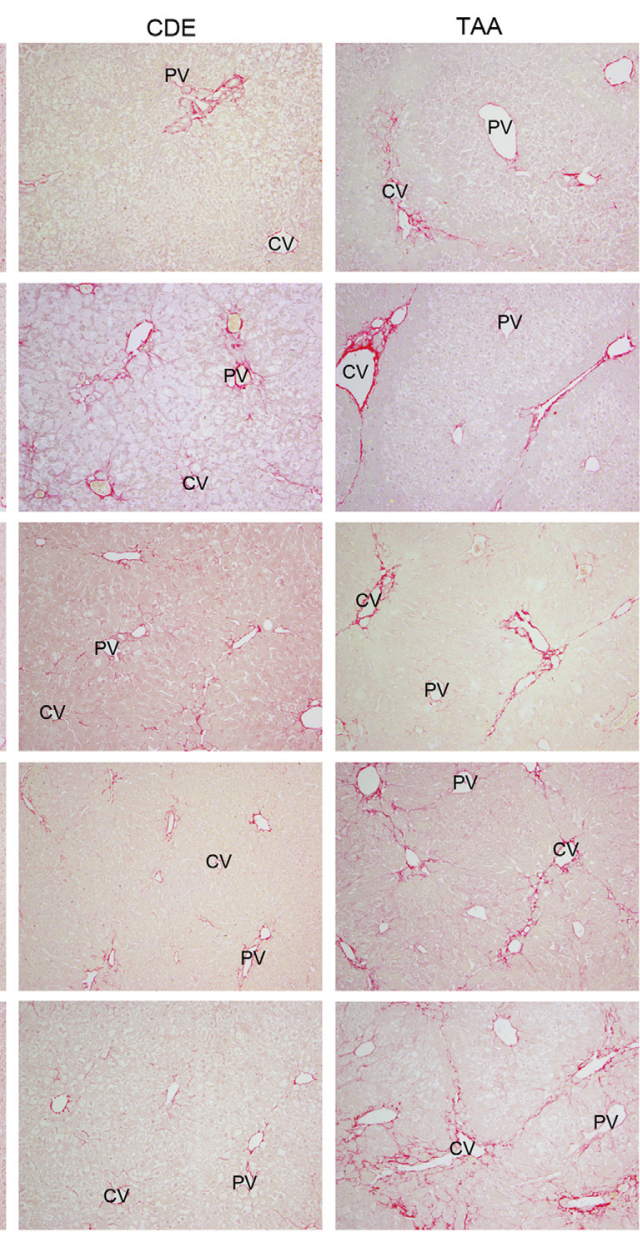
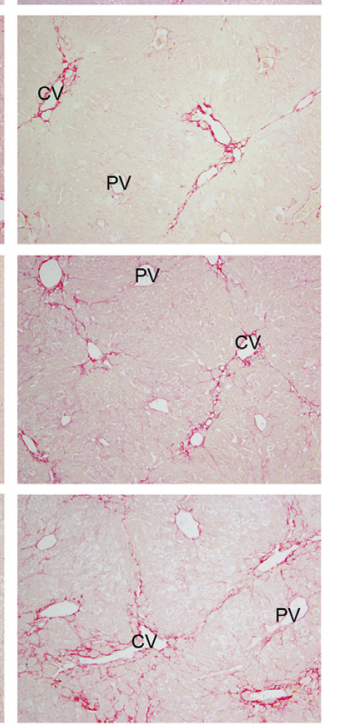

B

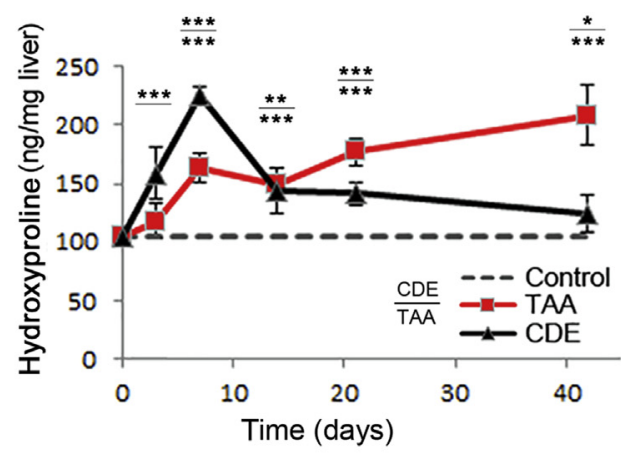

Figure $7 \quad C D E$ and TAA exposure induces the deposition of collagen and dictates a divergent fibrogenic response. A: Liver sections of control, CDE, and TAA mice were assessed for collagen deposition by Sirius Red staining at days 3, 7, 14, 21, and 42. Representative images are shown. Collagen accumulation was observed in response to both models. CDE treatment results in portal fibrosis at early time points (days 3 and 7) before normalizing toward day 42 . The TAA model induces central fibrosis starting at day 3 and progressing to centralcentral bridging toward day 42. B: Homogenized liver tissue was used to quantitate collagen deposition by measuring the corresponding hydroxyproline level. Hydroxyproline levels were calculated as microgram per milligram liver tissue. In CDE-fed mice the hydroxyproline concentration increases, peaking at day 7, and returns to control levels thereafter. In contrast, TAA administration induces a progressive increase in hydroxyproline levels throughout the time course. Data are expressed as means \pm SEM. $n=4$ to 6 mice per group. ${ }^{*} P<0.05,{ }^{* *} P<0.01$, and ${ }^{* * *} P<0.001$ compared with control mice. Scale bar $=100 \mu \mathrm{m}$. Original magnification: $\times 100(A)$. CDE, choline-deficient, ethionine-supplemented; $\mathrm{CV}$, central vein; PV, portal vein; TAA, thioacetamide. characterize the model of choice before the regimen as well as the appropriate time points are selected to study specific processes.

The CDE diet and TAA supplementation regimens are both commonly used to experimentally induce liver injury, fibrosis, and HCC, and in the case of TAA also cholangiocarcinoma. $^{21,24,29,36}$ In this study, we have now comprehensively compared the two models during a 42-day period. The injury induction phase was represented by days 3 and 7, the establishment phase by days 14 and 21, and the maintenance phase by day 42 . Our data clearly indicate that the spatial and temporal kinetics differ significantly between the two CLD regimens. We found that injury, hepatic fat loading, inflammation, and fibrosis all peak during the induction phase of the CDE diet before returning to control levels in the establishment and maintenance phase. This flare is sufficient to orchestrate an LPC response that reaches a steady state from approximately 2 weeks, most likely reflecting an equilibrium of LPC activation and lineage maturation. In contrast, the TAA model produces a more severe, progressive (chronic) phenotype with disease parameters persistently upregulated or gradually increasing throughout the study. The succession of events is therefore significantly different in both regimens. For CDE, the succession is liver injury induction, inflammation, fibrosis and LPC response, alleviation or regression, and at later time points HCC (data not shown ${ }^{21}$ ). For TAA, the succession is liver injury induction, inflammation, fibrosis and LPC response, progressive aggravation, cirrhosis, and at later time points $\mathrm{HCC}$ and cholangiocarcinoma (data not shown ${ }^{29,36}$ ).

Our study indicated that CDE feeding is associated with excessive fat loading in the parenchyma, most likely caused by reduced secretion of very low-density lipoproteins, which in turn leads to increased oxidative stress, ${ }^{26,37}$ instigating the molecular and cellular injury cascade emanating from periportal areas. TAA, on the other hand, is a thiono-sulfurcontaining hepatotoxin that is converted via dioxygen and superoxide anion to hydrogen peroxide in pericentral regions, thereby directly causing oxidative stress, lipid peroxidation, and centrilobular necrosis. ${ }^{28}$ It is therefore not surprising that CDE-fed mice had inflammation in periportal and parenchymal areas, whereas the TAA regimen induced a persistent pericentral inflammatory response, reflective of the injury present in this lobular region. The accumulation of inflammatory cells may then orchestrate the initiation of the regeneration process by releasing mediating factors, such as cytokines and growth factors, that are known to activate and 
maintain either or both key cellular players, HSCs, and LPCs. These key players include tumor necrosis factor-like weak inducer of apoptosis, ${ }^{24}$ tumor necrosis factor, ${ }^{38}$ lymphotoxin $\beta,^{13}$ IL- $6,{ }^{39}$ interferon- $\gamma,{ }^{40}$ and hepatocyte growth factor, ${ }^{41}$ which we found to be upregulated in both models, yet with different expression dynamics.

In the CDE model, immune cells and myofibroblasts were present periportally from the induction phase, which we have found to facilitate LPC activation ${ }^{24,34}$ and cytokine crosstalkmediated migration of HSCs and LPCs from portal areas into the hepatic parenchyma. ${ }^{13}$ In contrast, TAA is known to induce centrilobular damage, and immune cells were therefore attracted to central areas, where they, together with sinusoidal endothelial cells and injured hepatocytes, may activate HSCs. The cellular injury and regeneration niche (that we propose to consist of closely associated inflammatory cells, LPCs, and/or the ductular reaction and activated HSCs) was only identified during later injury phases when panCK ${ }^{+}$structures were detected pericentrally.

Interestingly, immunofluorescent co-localization analysis of $\mathrm{A} 6$ and panCK staining revealed that $\mathrm{CDE}$ feeding mainly induced the double-positive LPC subpopulation, which emerged in periportal fields and migrated toward injured parenchymal areas. TAA on the other hand induced $\mathrm{A}^{+} / \mathrm{panCK}^{+}$cells and to a lesser extent also a population of $\mathrm{A}^{-} / \mathrm{panCK}^{+}$cells, which were mainly seen in central areas at later injury stages, co-existing in the injury and regeneration niche with $\mathrm{A}^{+} / \mathrm{panCK}^{+}$cells.

Livers of both the CDE and TAA model had deposition of extracellular matrix components, however to varying degrees, resulting in divergent degrees and patterns of fibrosis. In the CDE model, periportal fibrosis was induced; however, fibrosis eventually resolved to return to control levels after an initial peak in the induction phase, as indicated by immunofluorescent detection of $\alpha-\mathrm{SMA}^{+}$myofibroblasts, mRNA expression of fibrosis mediators, and Sirius Red-visualized, and hydroxyproline-quantitated, collagen deposition. This fibrosis pattern is typically observed in autoimmune or chronic viral hepatitis and chronic biliary diseases or cholestasis. ${ }^{42}$ In contrast, investigation of the same parameters in the TAA model revealed gradually increasing fibrosis in central areas, which progressed toward cirrhosis during the injury establishment and maintenance phase, a pattern usually observed in fibrosis, resulting from alcoholic or nonalcoholic steatohepatitis. $^{42}$ Interestingly, some previous studies using TAA to induce CLD have also reported portal, portal-toportal bridging, or portal-to-central bridging fibrosis, as well as inflammatory cell accumulation in portal areas. ${ }^{43-46}$ It is important to note that TAA induces severe morphologic changes in hepatic lobules, including irregular patterns of portal tracts and central veins, ductular reactions, and high vascularization directed to fibrotic areas, ${ }^{45,47,48}$ providing a rich feeding ground for potential misinterpretation with regard to clear identification of portal as opposed to central areas. We cannot rule out that studies from other groups using TAA resulted in increased disease activity in periportal areas because results in experimental CLD greatly depend on the genetic background of the animals, concentration and administration route of the disease-inducing agent, and indeed the point in time of the experimental design. However, our data emphasize that it is fundamental to perform detailed time course analyses instead of snapshot evaluations at later time points when the liver architecture is already well distorted to follow histologic changes and thus correctly interpret results. Our immunofluorescent data identifying and following $\mathrm{CD}_{4}{ }^{+}$, panCK ${ }^{+}$, and $\alpha-\mathrm{SMA}^{+}$cells over the course of 6 weeks provide clear evidence that periportal expansion of LPCs is limited in the TAA regimen, and both inflammation and fibrosis are predominantly provoked in the central areas. At later stages of TAA-induced injury, $\mathrm{A}^{+}$or panCK ${ }^{+}$ductular structures and LPCs also appear in central areas, tempting to misinterpret the local histology as portal instead of central. However, when we immunofluorescently stained 20-week TAA-treated livers that progress to cirrhosis with nodule formation using panCK as a biliary cell and LPC marker together with F4/80 (liver-resident macrophages), CD11b (monocyte-derived macrophages), or $\alpha$-SMA (myofibroblasts), we observed a perpetuation of established patterns and confirmed clearly discernable central fields as the major site of inflammatory, fibrogenic, and LPC-associated processes (Supplemental Figure S8). This finding emphasizes the importance of performing time course analyses of histologic injury coupled with immunostaining for the multiple cell populations involved to clearly distinguish between divergent lobular regions of hepatic injury, inflammation, fibrogenesis, and regeneration in models of CLD.

Taken together, this detailed comparison of CDE- and TAA-induced liver injury has revealed remarkable differences in the cellular and underlying molecular dynamics, creating distinct disease establishment and progression patterns, and will serve as a valuable basis for future research using these two common models of experimental CLD.

\section{Acknowledgments}

Rat anti-A6 antibody was a gift from Dr. Valentina Factor (National Cancer Institute, Bethesda, MD).

Author contributions were as follows: J.K.-G., experiment design and execution, data analysis and figure assembly, manuscript preparation, and editing; B.J.D., preliminary time-course experiments, experiment design and execution, and manuscript editing; C.A.G., provision of study material, manuscript editing; G.M., evaluation of fibrosis patterns; N.A.S., experiment design and manuscript editing; G.A.R., study funding and manuscript editing; G.W.M., provision of study material study funding and manuscript editing; C.L.E., experiment design and execution, data interpretation, and manuscript editing; J.K.O., study funding, data interpretation, and manuscript editing; J.E.E.T.-P., study funding, conception and 
approach, experiment design, data interpretation, manuscript preparation and editing, and the final approval of the manuscript.

\section{Supplemental Data}

Supplemental material for this article can be found at http://dx.doi.org/10.1016/j.ajpath.2016.03.005.

\section{References}

1. Chen CL, Yang HI, Yang WS, Liu CJ, Chen PJ, You SL, Wang LY, Sun CA, Lu SN, Chen DS, Chen CJ: Metabolic factors and risk of hepatocellular carcinoma by chronic hepatitis B/C infection: a followup study in Taiwan. Gastroenterology 2008, 135:111-121

2. Gouw AS, Clouston AD, Theise ND: Ductular reactions in human liver: diversity at the interface. Hepatology 2011, 54:1853-1863

3. Williams MJ, Clouston AD, Forbes SJ: Links between hepatic fibrosis, ductular reaction, and progenitor cell expansion. Gastroenterology 2014, 146:349-356

4. Forster N, Palmer JA, Yeoh G, Ong WC, Mitchell GM, Slavin J, Tirnitz-Parker J, Morrison WA: Expansion and hepatocytic differentiation of liver progenitor cells in vivo using a vascularized tissue engineering chamber in mice. Tissue Eng Part C Methods 2011, 17:359-366

5. Lu WY, Bird TG, Boulter L, Tsuchiya A, Cole AM, Hay T, Guest RV, Wojtacha D, Man TY, Mackinnon A, Ridgway RA, Kendall T, Williams MJ, Jamieson T, Raven A, Hay DC, Iredale JP, Clarke AR, Sansom OJ, Forbes SJ: Hepatic progenitor cells of biliary origin with liver repopulation capacity. Nat Cell Biol 2015, 17:971-983

6. Sackett SD, Li Z, Hurtt R, Gao Y, Wells RG, Brondell K, Kaestner KH, Greenbaum LE: Foxl1 is a marker of bipotential hepatic progenitor cells in mice. Hepatology 2009, 49:920-929

7. Shin S, Walton G, Aoki R, Brondell K, Schug J, Fox A, Smirnova O, Dorrell C, Erker L, Chu AS, Wells RG, Grompe M, Greenbaum LE, Kaestner KH: Foxl1-Cre-marked adult hepatic progenitors have clonogenic and bilineage differentiation potential. Genes Dev 2011, 25:1185-1192

8. Suzuki A, Sekiya S, Onishi M, Oshima N, Kiyonari H, Nakauchi H, Taniguchi H: Flow cytometric isolation and clonal identification of self-renewing bipotent hepatic progenitor cells in adult mouse liver. Hepatology 2008, 48:1964-1978

9. Kohn-Gaone J, Gogoi-Tiwari J, Ramm GA, Olynyk JK, TirnitzParker JE: The role of liver progenitor cells during liver regeneration, fibrogenesis, and carcinogenesis. Am J Physiol Gastrointest Liver Physiol 2016, 310:G143-G154

10. Boulter L, Lu WY, Forbes SJ: Differentiation of progenitors in the liver: a matter of local choice. J Clin Invest 2013, 123:1867-1873

11. Dwyer BJ, Olynyk JK, Ramm GA, Tirnitz-Parker JE: TWEAK and LTbeta Signaling during Chronic Liver Disease. Front Immunol 2014, 5:39

12. Grzelak CA, Martelotto LG, Sigglekow ND, Patkunanathan B, Ajami K, Calabro SR, Dwyer BJ, Tirnitz-Parker JE, Watkins DN, Warner FJ, Shackel NA, McCaughan GW: The intrahepatic signalling niche of hedgehog is defined by primary cilia positive cells during chronic liver injury. J Hepatol 2014, 60:143-151

13. Ruddell RG, Knight B, Tirnitz-Parker JE, Akhurst B, Summerville L, Subramaniam VN, Olynyk JK, Ramm GA: Lymphotoxin-beta receptor signaling regulates hepatic stellate cell function and wound healing in a murine model of chronic liver injury. Hepatology 2009, 49:227-239

14. Tirnitz-Parker JE, Olynyk JK, Ramm GA: Role of TWEAK in coregulating liver progenitor cell and fibrogenic responses. Hepatology 2014, 59:1198-1201

15. Dan YY, Yeoh GC: Liver stem cells: a scientific and clinical perspective. J Gastroenterol Hepatol 2008, 23:687-698

16. Clouston AD, Powell EE, Walsh MJ, Richardson MM, Demetris AJ, Jonsson JR: Fibrosis correlates with a ductular reaction in hepatitis C: roles of impaired replication, progenitor cells and steatosis. Hepatology 2005, 41:809-818

17. Lowes KN, Brennan BA, Yeoh GC, Olynyk JK: Oval cell numbers in human chronic liver diseases are directly related to disease severity. Am J Pathol 1999, 154:537-541

18. Prakoso E, Tirnitz-Parker JE, Clouston AD, Kayali Z, Lee A, Gan EK, Ramm GA, Kench JG, Bowen DG, Olynyk JK, McCaughan GW, Shackel NA: Analysis of the intrahepatic ductular reaction and progenitor cell responses in hepatitis $\mathrm{C}$ virus recurrence after liver transplantation. Liver Transpl 2014, 20:1508-1519

19. Wood MJ, Gadd VL, Powell LW, Ramm GA, Clouston AD: Ductular reaction in hereditary hemochromatosis: the link between hepatocyte senescence and fibrosis progression. Hepatology 2014, 59:848-857

20. Davies RA, Knight B, Tian YW, Yeoh GC, Olynyk JK: Hepatic oval cell response to the choline-deficient, ethionine supplemented model of murine liver injury is attenuated by the administration of a cyclooxygenase 2 inhibitor. Carcinogenesis 2006, 27:1607-1616

21. Knight B, Tirnitz-Parker JE, Olynyk JK: C-kit inhibition by imatinib mesylate attenuates progenitor cell expansion and inhibits liver tumor formation in mice. Gastroenterology 2008, 135:969-979. 979.e1

22. Lee KP, Lee JH, Kim TS, Kim TH, Park HD, Byun JS, Kim MC, Jeong WI, Calvisi DF, Kim JM, Lim DS: The Hippo-Salvador pathway restrains hepatic oval cell proliferation, liver size, and liver tumorigenesis. Proc Natl Acad Sci U S A 2010, 107:8248-8253

23. Akhurst B, Croager EJ, Farley-Roche CA, Ong JK, Dumble ML, Knight B, Yeoh GC: A modified choline-deficient, ethionine-supplemented diet protocol effectively induces oval cells in mouse liver. Hepatology 2001, 34:519-522

24. Tirnitz-Parker JE, Viebahn CS, Jakubowski A, Klopcic BR, Olynyk JK, Yeoh GC, Knight B: Tumor necrosis factor-like weak inducer of apoptosis is a mitogen for liver progenitor cells. Hepatology 2010, 52:291-302

25. Van Hul NK, Abarca-Quinones J, Sempoux C, Horsmans Y, Leclercq IA: Relation between liver progenitor cell expansion and extracellular matrix deposition in a CDE-induced murine model of chronic liver injury. Hepatology 2009, 49:1625-1635

26. Yao ZM, Vance DE: The active synthesis of phosphatidylcholine is required for very low density lipoprotein secretion from rat hepatocytes. J Biol Chem 1988, 263:2998-3004

27. Hunter AL, Holscher MA, Neal RA: Thioacetamide-induced hepatic necrosis. I. Involvement of the mixed-function oxidase enzyme system. J Pharmacol Exp Ther 1977, 200:439-448

28. Low TY, Leow CK, Salto-Tellez M, Chung MC: A proteomic analysis of thioacetamide-induced hepatotoxicity and cirrhosis in rat livers. Proteomics 2004, 4:3960-3974

29. Boulter L, Guest RV, Kendall TJ, Wilson DH, Wojtacha D, Robson AJ, Ridgway RA, Samuel K, Van Rooijen N, Barry ST, Wigmore SJ, Sansom OJ, Forbes SJ: WNT signaling drives cholangiocarcinoma growth and can be pharmacologically inhibited. J Clin Invest 2015, 125:1269-1285

30. Guest RV, Boulter L, Kendall TJ, Minnis-Lyons SE, Walker R, Wigmore SJ, Sansom OJ, Forbes SJ: Cell lineage tracing reveals a biliary origin of intrahepatic cholangiocarcinoma. Cancer Res 2014, 74:1005-1010

31. Biswas M, Chan JY: Role of Nrf1 in antioxidant response elementmediated gene expression and beyond. Toxicol Appl Pharmacol 2010, 244:16-20

32. Okuyama H, Nakamura H, Shimahara Y, Uyama N, Kwon YW, Kawada N, Yamaoka Y, Yodoi J: Overexpression of thioredoxin prevents thioacetamide-induced hepatic fibrosis in mice. J Hepatol 2005, 42:117-123

33. Hardwick RN, Fisher CD, Canet MJ, Lake AD, Cherrington NJ: Diversity in antioxidant response enzymes in progressive stages of human nonalcoholic fatty liver disease. Drug Metab Dispos 2010, 38: 2293-2301 
34. Elsegood CL, Chan CW, Degli-Esposti MA, Wikstrom ME, Domenichini A, Lazarus K, van Rooijen N, Ganss R, Olynyk JK, Yeoh GC: Kupffer cell-monocyte communication is essential for initiating murine liver progenitor cell-mediated liver regeneration. Hepatology 2015, 62:1272-1284

35. Kofman AV, Morgan G, Kirschenbaum A, Osbeck J, Hussain M, Swenson S, Theise ND: Dose- and time-dependent oval cell reaction in acetaminophen-induced murine liver injury. Hepatology 2005, 41: $1252-1261$

36. Darweish MM, Abbas A, Ebrahim MA, Al-Gayyar MM: Chemopreventive and hepatoprotective effects of Epigallocatechin-gallate against hepatocellular carcinoma: role of heparan sulfate proteoglycans pathway. J Pharm Pharmacol 2014, 66:1032-1045

37. Aharoni-Simon M, Hann-Obercyger M, Pen S, Madar Z, Tirosh O: Fatty liver is associated with impaired activity of PPARgammacoactivator 1alpha (PGClalpha) and mitochondrial biogenesis in mice. Lab Invest 2011, 91:1018-1028

38. Knight B, Yeoh GC: TNF/LTalpha double knockout mice display abnormal inflammatory and regenerative responses to acute and chronic liver injury. Cell Tissue Res 2005, 319:61-70

39. Matthews VB, Klinken E, Yeoh GC: Direct effects of interleukin-6 on liver progenitor oval cells in culture. Wound Repair Regen 2004, 12 : 650-656

40. Brooling JT, Campbell JS, Mitchell C, Yeoh GC, Fausto N: Differential regulation of rodent hepatocyte and oval cell proliferation by interferon gamma. Hepatology 2005, 41:906-915

41. Ishikawa T, Factor VM, Marquardt JU, Raggi C, Seo D, Kitade M, Conner EA, Thorgeirsson SS: Hepatocyte growth factor/c-met signaling is required for stem-cell-mediated liver regeneration in mice. Hepatology 2012, 55:1215-1226

42. Ferrell L: Liver pathology: cirrhosis, hepatitis, and primary liver tumors Update and diagnostic problems. Mod Pathol 2000, 13:679-704

43. Aydin AF, Kusku-Kiraz Z, Dogru-Abbasoglu S, Gulluoglu M, Uysal M, Kocak-Toker N: Effect of carnosine against thioacetamideinduced liver cirrhosis in rat. Peptides 2010, 31:67-71

44. Kornek M, Raskopf E, Guetgemann I, Ocker M, Gerceker S, Gonzalez-Carmona MA, Rabe C, Sauerbruch T, Schmitz V: Combination of systemic thioacetamide (TAA) injections and ethanol feeding accelerates hepatic fibrosis in $\mathrm{C} 3 \mathrm{H} / \mathrm{He}$ mice and is associated with intrahepatic up regulation of MMP-2, VEGF and ICAM-1. J Hepatol 2006, 45:370-376

45. Patsenker E, Popov Y, Stickel F, Schneider V, Ledermann M, Sagesser H, Niedobitek G, Goodman SL, Schuppan D: Pharmacological inhibition of integrin alphavbeta3 aggravates experimental liver fibrosis and suppresses hepatic angiogenesis. Hepatology 2009, 50:1501-1511

46. Wallace MC, Hamesch K, Lunova M, Kim Y, Weiskirchen R, Strnad P, Friedman SL: Standard operating procedures in experimental liver research: thioacetamide model in mice and rats. Lab Anim 2015, 49:21-29

47. Gao JH, Wen SL, Yang WJ, Lu YY, Tong H, Huang ZY, Liu ZX, Tang CW: Celecoxib ameliorates portal hypertension of the cirrhotic rats through the dual inhibitory effects on the intrahepatic fibrosis and angiogenesis. PLoS One 2013, 8:e69309

48. Lee TY, Chang HH, Wen CK, Huang TH, Chang YS: Modulation of thioacetamide-induced hepatic inflammations, angiogenesis and fibrosis by andrographolide in mice. J Ethnopharmacol 2014, $158 \mathrm{Pt}$ A: 423-430 